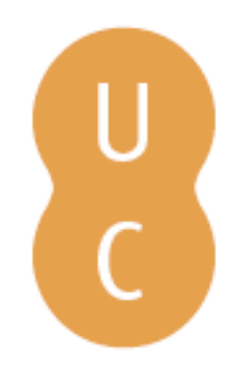

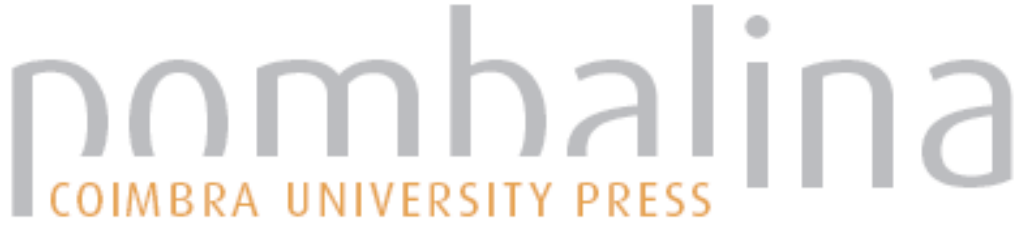

\section{A Phýsis Grega e o Brasil: as viagens de Von Martius}

\author{
Autor(es): $\quad$ Schmitt, Alexandre
}

Publicado por: Imprensa da Universidade de Coimbra

URL

persistente: $\quad$ URI:http://hdl.handle.net/10316.2/37046

DOI: $\quad$ DOI:http://dx.doi.org/10.14195/978-989-26-1043-6_11

Accessed : $\quad$ 26-Apr-2023 13:34:38

A navegação consulta e descarregamento dos títulos inseridos nas Bibliotecas Digitais UC Digitalis, UC Pombalina e UC Impactum, pressupõem a aceitação plena e sem reservas dos Termos e Condições de Uso destas Bibliotecas Digitais, disponíveis em https://digitalis.uc.pt/pt-pt/termos.

Conforme exposto nos referidos Termos e Condições de Uso, o descarregamento de títulos de acesso restrito requer uma licença válida de autorização devendo o utilizador aceder ao(s) documento(s) a partir de um endereço de IP da instituição detentora da supramencionada licença.

Ao utilizador é apenas permitido o descarregamento para uso pessoal, pelo que o emprego do(s) título(s) descarregado(s) para outro fim, designadamente comercial, carece de autorização do respetivo autor ou editor da obra.

Na medida em que todas as obras da UC Digitalis se encontram protegidas pelo Código do Direito de Autor e Direitos Conexos e demais legislação aplicável, toda a cópia, parcial ou total, deste documento, nos casos em que é legalmente admitida, deverá conter ou fazer-se acompanhar por este aviso.

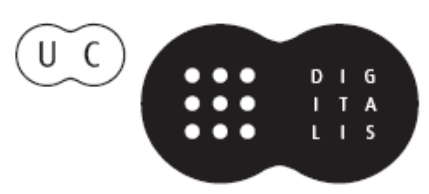


politica no Brasil do sécu

Categorias aristotélicas por Silvestre Pinheiro Ferreira - Musas errantes: tesouros da Antiguidade Clássica no labirinto da Biblioteca Nacional Brasileira - Eudoro de Sousa e a Mitologia • Câmara Cascudo em defesa de Epicuro - Medéia carioca - Ecos de Platão em Vergílio Ferreira - Imaginário clássico na poesia de António Arnaut - Motivos clássicos na poesia novilatina em Portugal: Manuel da Costa - Uma Ifigénia portuguesa: "Noite escura" de João Canijo • Uma leitura de Mau Tempo no Canal de Vitorino Nemésio $\bullet A$ phýsis grega e o Brasil: as viagens de Von Martius $\bullet$ Fantasia para dois coronéis e uma piscina. Ecos clássicos num contexto do séc. XX

\section{A RECEPÇÃO DOS CLÁSSICOS EM PORTUGAL E NO BRASIL}

Maria de Fátima Silva Maria das Graças de Moraes Augusto COORDENAÇÃo 


\section{SÉRIE MITO E (RE)ESCRITA}

ISSN: $2182-8814$

\section{PERIODICIDADE: Anual}

Apresentação: Poetas, pintores, escultores, na Antiguidade, familiarizados com mitos antigos de deuses e de homens, que cristalizavam experiências, interrogaçóes, respostas quanto à existência do homem no tempo e no mundo, em mitos se inspiraram, em contínua criação-recriaçẩo, para neles verterem a sua própria experiência temporal, com todos os desassossegos e inquietaçóes, com todo o espanto, horror ou encantamento pela excecionalidade da ação humana, que rasga ou ilumina fronteiras de finitude. Esses percursos da criação merecem, hoje, a atenção e análise dos Estudos Literários e, como não podia deixar de ser, dos Estudos Clássicos, muito peculiarmente. Importa, pois, proceder à publicação sistemática de estudos deste cariz, que se destaquem pela qualidade científica e pela originalidade, sendo dedicados, sobretudo, a autores de língua portuguesa. Assim se dá corpo à linha editorial MITO E (RE)ESCRITA.

Este livro, realizado no âmbito do Convénio de Cooperação Académica entre o CECH - Centro de Estudos Clássicos e Humanísticos da UC - e o PRAGMA - Programa de Estudos de Filosofia Antiga da UFRJ -, reúne um conjunto de estudos sobre a recepçáo de temas e modelos greco-latinos na literatura e cultura de Portugal e Brasil.

A sua originalidade resulta da participação de diferentes culturas e das especialidades académicas diversas dos investigadores que nele participam, provenientes da Literatura, da Filosofia e da História Antiga. O lapso de tempo abrangido, que vai do séc. XVI ao XX, permite uma visáo de conjunto da evoluçáo operada no perfil cultural de ambos os países e na definição de um trajeto em boa parte comum. 


\title{
A Phýsis Grega e o Brasil: as viagens de Von Martius
}

(Greek physis in Brazil: the travels of Von Martius)

\author{
Alexandre Schmitt \\ Universidade Federal do Rio de Janeiro \\ (alexandre.schmitt01@gmail.com)
}


Página deixada propositadamente em branco 
Resumo - O objetivo deste artigo é investigar as referências ao universo clássico em algumas passagens das Tabulae Physiognomicae de Flora Brasiliensis, em especial, nas passagens existentes nas pranchas I, II, VI, VII, VIII e IX, visando a uma compreensão dos objetivos de Carl von Martius na utilização desse artifício para a descrição das paisagens brasileiras apresentadas nessas pranchas.

Palavras-chave - Flora Brasiliensis. Von Martius. Phýsis.

Aвstract - The objective of this paper is to investigate the references to the classical universe in some passages of Flora Brasiliensis' Tabulae Physiognomicae in particular the passages on boards I, II, VI, VII, VIII and IX, aiming to understand the objectives of Carl von Martius' use of this device for the description of the Brazilian landscapes presented in these boards.

Keywords - Flora Brasiliensis. Von Martius. Phýsis.

\section{Introdução}

No ano de 1815, a Real Academia de Ciências de Munique começa a organizar, por ordens do rei Maximiliano José I da Baviera, uma expedição científica para desbravar o interior da América do Sul. A intenção inicial era que ela desembarcasse em Buenos Aires, cruzasse os Andes e seguisse ao norte, em direção ao Equador ou à Venezuela, sendo comandada por Johann Baptist von Spix, zoólogo, e integrada também por Carl Friedrich von Martius, botânico, ambos membros da Academia muniquense. A expedição, contudo, sofre um atraso, que acaba sendo decisivo na determinação dos rumos que ela veio a tomar. Em breve, na Áustria, país comandado pelo genro de Maximiliano José I, Francisco I, iniciar-se-iam os preparativos para a viagem de sua filha, Leopoldina, para o Brasil, em virtude de seu casamento com Pedro. O Museu de História Natural de Viena preparava, então, uma expedição científica em direção ao interior do Brasil e Maximiliano José I, que tinha ótimas relaçóes com Francisco I, conseguiu que os seus naturalistas bávaros a integrassem.

A expedição chega ao porto do Rio de Janeiro em julho de 1817. Spix e Martius permanecem seis meses na cidade onde organizam o roteiro de sua viagem, decidindo, então, ao final desse prazo, partir sem os demais integrantes austríacos da expedição, visto que esses faziam parte da comitiva de Dona Leopoldina cuja vinda para o Brasil sofrera um grande atraso.

A expedição dos bávaros passou pela província de São Paulo, por Minas Gerais e rumou para o norte do país, cruzando todo o sertão nordestino e adentrando a Amazônia por meio do rio Amazonas e do Solimóes. Finalmente, em abril de 1820, os dois naturalistas partem de Belém de 
volta para Munique, onde seus relatos de viagem e a fabulosa coleção de espécimes botânicas, de animais e de artefatos minerais e etnográficos por eles coletados será organizada. Em 1823, é editado o primeiro volume de Reise in Brasilien - Viagem pelo Brasil, obra que será finalmente completada com a publicação de seu terceiro e último volume em 1831, já sem a colaboração de Spix, que falecera em 1826. Simultaneamente à edição dos seus relatos de viagem, Spix e Martius publicarão também o resultado das suas investigaçóes botânicas e zoológicas. No mesmo período, entre 1823 e 1831, três volumes da Nova Genera et Species Plantarum Brasiliensium serão publicados por Martius e, em 1840, depois de uma tentativa fracassada de publicação ocorrida em 1833, será editado o primeiro fascículo de Flora Brasiliensis, patrocinado por Fernando I, imperador austríaco, e pelo rei da Baviera, Ludovico I. Após a abdicação do soberano bávaro, a obra, a partir de 1850, passará a ser financiada por Pedro II do Brasil, tendo a sua publicação na íntegra sido completada apenas em 1906, sessenta e seis anos, portanto, após a publicação do primeiro fascículo. Martius falece em 1868, completando 46 fascículos, assumindo, então, a coordenação da edição, August W. Eichler e, posteriormente, Ignatz Urban. Serão ao todo 130 fascículos, com 20.733 páginas, que depois serão reorganizados em 40 volumes, constituindo a maior obra já publicada sobre a flora de um país ${ }^{1}$.

O primeiro volume é dividido em seis partes, sendo a primeira delas as Tabulae Physiognomicae Explicatae. As Tabulae Physiognomicae Explicatae compreendem descriçóes de cinquenta e nove pranchas litografadas, apresentando a vegetaçáo e o ecossistema brasileiros, além do primeiro ensaio publicado sobre a fitogeografia do Brasil. Martius propóe uma divisão do território brasileiro em cinco zonas fitogeográficas: Náiades (que corresponde à Floresta Amazônica); Hamadríades (a caatinga); Oréades (as montanhas e o cerrado do Planalto Central); Dríades (a Floresta Atlântica) e Napeias (as matas de Araucária e os Pampas). Essa divisão consta de um dos mapas que integram esse primeiro volume. Portanto, a úmida floresta amazônica é denominada segundo a ninfa das fontes e córregos do universo mitológico grego; a Caatinga é o espaço das ninfas das demais árvores; a Floresta Atlântica constitui a terra das ninfas associadas aos carvalhos; o Planalto Central e as montanhas, o espaço das ninfas protetoras das montanhas; e os Pampas e as Araucárias do sul do Brasil, a terra das ninfas asso-

1 Para uma descrição detalhada de todos os aspectos históricos da viagem e da produção científica de Martius, ver Lisboa: 1997. 
ciadas a vales, colinas e depressóes. O espaço fitogeográfico brasileiro, desse modo, é descrito com referência a elementos do universo mitológico grego.

Essa é apenas uma das inúmeras referências que são feitas nas Tabulae Physiognomicae ao universo literário clássico. Além delas, concepçôes gregas acerca da phýsis são também frequentemente evocadas para descrever as paisagens brasileiras. O objetivo deste artigo é investigar as referências ao universo clássico em algumas passagens das Tabulae Physiognomicae, em especial nas passagens existentes nas pranchas I, II, VI, VII, VIII e IX, visando a uma compreensão dos objetivos de Martius na utilização desse artifício para a descrição das paisagens brasileiras apresentadas nessas pranchas.

Para tanto, inicialmente se discorrerá sobre o contexto histórico-cultural da expedição de Martius e da elaboração do seu Flora Brasiliensis, dando-se destaque à concepção de natureza ali existente. Depois disso, serão comentadas as passagens nas pranchas acima enumeradas que fazem referência ao universo clássico.

\section{O contexto histórico-cultural}

As descriçóes apresentadas por Martius nas Tabulae Physiognomicae apresentam uma concepção organicista da natureza, marca do romantismo alemão, em contraposição a uma visão anterior, notavelmente mecanicista. Há, inclusive, certo holismo e certo panteísmo na descriçâo do viajante, e mesmo, certo vitalismo como se pode notar em algumas passagens que serão elencadas neste trabalho.

Para que se possa compreender o porquê de uma postura não meramente taxonômica da paisagem, mas o uso de uma abordagem verdadeiramente poética para dela tratar, é fundamental que seja exposto o contexto histórico-cultural em que foi fomentada a obra de Martius. Ganham destaque especial: a) o estilo estético-científico proposto por Alexander von Humboldt na descrição dos seus relatos de viagem; b) a Naturphilosophie - filosofia da natureza - de Schelling; e c) a influência do pensamento de Goethe.

A importância do estilo estético-científico de Alexander von Humboldt ${ }^{2}$ na elaboração do estilo narrativo de Martius é atestada por inúmeros au-

2 Note-se que Martius faz na prancha XXVIII das Tabulae Physiognomicae da Flora Brasiliensis uma referência elogiosa a Humboldt: "Aquele ilustríssimo viajante do mundo e também seu retratista, Alexander von Humboldt, a quem devemos como que os fundamentos da fisionomia das plantas, entre muitas outras coisas, na obra (Ansichten der Natur, 1808: 322) diz que era essa a índole dos primeiros tempos das florestas primitivas, que apareçam impenetráveis, [...]”. Ver Martius 1996: 97. 
tores. Humboldt estivera em inúmeras expediçóes na América Latina entre 1799 e 1804. Em 1807, ele publica Ansichten der Natur - Quadros da Natureza, e, no prefácio à sua primeira edição, ele explicita não só o objetivo de sua obra, como também o estilo e o método que adota para a sua elaboração:

A visão da Natureza em uma escala amplificada, a exposição da ação concorrente de várias forças ou poderes, e a renovação do prazer que a perspectiva imediata [da cena tropical] proporciona às mentes sensíveis são os objetivos que eu propus a mim mesmo. Embora cada um dos tratados [de que a minha obra consiste] deva formar um todo completo em si mesmo, uma tendência comum deve permear a todos. Esse tratamento estético dos objetos da história natural está sujeito a grandes dificuldades de composição, não obstante o poder e a flexibilidade da nossa língua materna. [...] Quando os sentimentos e a imaginação falam mais alto, o estilo se degenera em uma leve prosa poética. Mas eu não preciso aqui descrever de forma mais completa os perigos que eu temo que as páginas seguintes mostraráo que eu nem sempre consegui evitar. Contudo, não obstante as falhas que eu posso mais facilmente perceber do que evitar, eu espero proporcionar ao leitor uma porçáo daquele prazer que a mente sensível recebe da contemplação imediata da natureza. [...] Ao longo de todo o trabalho, eu apontei a infalível influência que a natureza física exerce sobre o sentimento moral da humanidade e sobre o seu destino. Essas páginas são dedicadas preferencialmente às mentes atormentadas ${ }^{3}$.

Em outras palavras, Humboldt ao mesmo tempo em que defende uma utilização minuciosa de aparatos científicos para descrever a natureza, visando a desvendar o conjunto de forças que harmonicamente a constituem, preconiza um tratamento estético de seus textos, de forma a gerar no leitor uma espécie de prazer que a contemplação física da natureza proporciona. O seu relato assume, nessas situações, o caráter de uma espécie de prosa poética. Trata-se, portanto, de uma fusão entre ciência e poesia, uma espécie de mescla entre o empirismo baconiano e a filosofia da natureza de Goethe e de Schelling ${ }^{4}$. Ecos de Rousseau são perfeitamente audíveis nessa forma narrativa, que carrega consigo e, mesmo constitui, uma verdadeira

\footnotetext{
3 Humboldt 1808: v-viii. Tradução nossa.

4 Ver Vitte 2006: 40.
} 
filosofia da natureza. É, aliás, como uma espécie de filosofia da natureza que Humboldt descreve o seu próprio trabalho:

[...] a filosofia da natureza se desprende das formas vagas e poéticas próprias de sua origem, adota um caráter mais severo, inclui o valor das observaçóes e já não se entrega à adivinhação como antes, e nem à relação e ao raciocínio5.

Essa postura de Humboldt aponta para uma espécie de síntese de ideias da ilustração e de ideais românticos ${ }^{6}$. Assim, se o iluminismo é marcado por uma perspectiva mecânica do mundo, derivada das descobertas newtonianas, e por uma crença na razão como meio de compreensão da realidade e na criação de um mundo justo, o romantismo será fruto justamente de uma crise do primeiro, diante da falência da promessa de alcance dos ideais de igualdade, fraternidade e liberdade. A sociedade é vista como injusta e opressora e o indivíduo é redescoberto como figura primordial, ressaltando-se o seu "mundo interior", constituindo o "mundo externo", em grande parte, apenas uma extensão do primeiro. A natureza será vista então como o elemento que proporciona a liberdade de que o homem precisa, elemento que o consola das tormentas da existência, "uma grande rede viva de relações, um grande "eu"" "' "um organismo capaz de desenvolver criativamente suas potencialidades inerentes, ao longo do tempo"

Ela será vista como uma unidade harmônica e o resultado mais importante do seu estudo racional será a compreensão do imenso agregado de coisas e de forças que se relacionam e geram essa harmonia'.

Se Humboldt constitui uma influência essencial para a confecção do estilo de Martius, Goethe não representa uma influência menor. Martius e Goethe se correspondiam com frequência. Em setembro de 1824, um contato pessoal é estabelecido por ambos ${ }^{10}$. Nasce assim um intercâmbio científico e cultural dos mais fecundos, o qual se enraíza especialmente nas concepçóes panteístas de que partilhavam o velho poeta de Weimar e o jovem botânico. A relação entre Goethe e Martius gerará uma influência

\footnotetext{
5 Humboldt 2005: 18-19. Tradução nossa.

6 Ver Springer 2009: 11.

7 Springer 2009: 10.

8 Springer 2009: 10.

9 Ver Humboldt 2005: 19. Tradução nossa.

10 Ver Mazzari 2010: 184 e Lisboa 1997: 74-75.
} 
mútua tanto na obra do primeiro quanto na do segundo. Goethe leu e releu a Flora Brasiliensis de Martius até o fim de sua vida, e uma teoria de Martius sobre a tendência espiral das plantas gerará um certo entusiasmo nele, sendo peça importante na elaboração do Fausto $\mathrm{II}^{11}$. Quanto a Martius, esse leva consigo para a sua expedição o Fausto e o relê constantemente ${ }^{12}$. Além disso, A Metamorfose das Plantas também é outra leitura frequente, como ele mesmo atesta em uma carta a Goethe em que enviava ao mestre de Weimar a primeira parte de seu tratado Palmae Brasiliensis ${ }^{13}$.

Dois outros pontos da relação entre Martius e Goethe merecem ainda atenção ${ }^{14}$ : Martius e o botânico Nees von Esenbeck dão o nome de Goethea a um tipo de malvácia endêmica no Brasil e Goethe fica muito feliz e envaidecido com isso; e Goethe saudará Martius, quando da sua estada em Weimar, com um dístico com uma tendência nitidamente panteísta: "Was hiesse wohl di Natur ergründen? Gott ebenso draussen wie innen finden" ("O que significa entáo perscrutar a Natureza? Encontrar Deus tanto fora como dentro de si" $)^{15}$. Espinosa fora uma importante influência na concepção do pensamento de Goethe e, curiosamente, também na concepção do pensamento de Martius ${ }^{16}$ : em maio de 1825 ele dirá em carta a Goethe que nada o preparara tanto para a viagem brasileira como o pensamento de Espinosa e a leitura do Fausto ${ }^{17}$. Para Goethe, a Natureza é Deus. Em outras palavras, ela é uma das infinitas dimensóes do ser de Deus e dos atributos externos do Divino.

11 Sobre a influência mútua dos dois autores, ver Mazzari 2010: 185-195.

12 Ver Lisboa 1997: 74.

13 Ver Mazzari 2010: 191. Nesse texto, Goethe relata a sua doutrina, segundo a qual todos os órgãos de uma planta constituem formas de folhas transformadas. Essa ideia deriva do conceito de Urphänomen do próprio Goethe - fenômeno originário, segundo o qual haveria uma forma originária a partir da qual todas as plantas (e todos os animais) haviam se originado. Era uma espécie de forma primeva.

14 Ver Mazzari 2010: 186.

15 Ver Mazzari 2010: 186.

16 A referência e o elogio a Goethe aparecem também nas Tabulae Physiognomicae de Flora Brasiliensis. Na prancha XXIII, Martius cita: "A esta singular e quase hórrida espécie de natureza enquadra-se o que disse o nosso maior poeta, Goethe, cuja antiga familiaridade estará sempre entre os maiores presentes do destino: Mas porém quem é ele?/ Entre os arbustos perde-se o seu rastro,/ Atrás dele fecham-se/ Os arbustos/ As hastes da grama erguem-se novamente/O vazio o engole!". Ver Martius 1996: 88.

17 Ver Mazzari 2010: 186. 
Em uma carta de 18 de maio de 1825, Martius esclarece, sobre a sua concepção de natureza, que o que importa é perceber

[...] o espírito da natureza, que justamente não pode ser guarnecido por diagnóstico algum. Mas ele está vivo e presente, eternamente solicitando a mente humana, atraindo e rejeitando-a; trata-se de um grande jogo, que seria terrível, se não se pudesse crer que não finda com a morte, e sim que se perpetua nos éons cada vez mais encantado, enobrecido e apoteosado ${ }^{18}$.

Ou seja, Martius parece deixar claro que, mais do que fazer taxonomias e classificaçóes, ele tem em mente não só uma concepção de unidade da natureza, mas vê nela uma certa expressão de um espírito eterno. Isso remete diretamente à filosofia da natureza de Schelling.

Spix conhecera Schelling em Würzburg, onde estudara teologia em um seminário episcopal, após doutorar-se em filosofia na universidade de Bamberg. Será o próprio Schelling que, anos mais tarde, após tomar posse como membro da Real Academia de Ciências de Munique e dirigir a Academia de Artes, indicará o nome de Spix ao ministro de Estado, para um financiamento de uma viagem de estudos à França, à Itália e à Suíça ${ }^{19}$.

Schelling se opóe a uma visão mecanicista da natureza, propondo uma visão holística. Para ele, os fenômenos naturais seriam a manifestação de uma mesma atividade, uma espécie de força. Caberia à filosofia da natureza explicar como uma atividade absoluta e infinita se apresenta empiricamente no finito. A filosofia da natureza deveria, desse modo, começar pela pesquisa empírica, pois a identificaçáo pura e simples da atividade absoluta não basta. Em Da alma no mundo, ele tenta mostrar como a natureza se desdobra de forma individual como um impulso universal para uma organização. Nesse contexto, o naturalista desempenha um papel importante. A Naturphilosophie, portanto, não implica uma ignorância dos dados individuais oriundos da pesquisas empíricas, mas, muito pelo contrário, deve procurar sintetizar esses dados. Em outras palavras, "para mostrar como a natureza opera em escala universal, deve-se primeiro ver como ela opera no mundo concreto e tangível"20.

\footnotetext{
18 Martius apud Lisboa 1997: 75.

19 Sobre a relação de Spix e Schelling, vide Lisboa 1997: 52-53.

20 Foster 2008: 275.
} 


\section{A Phýsis grega nas Tabulae Physiognomicae}

Um levantamento das referências diretas ao universo clássico nas Tabulae Physiognomicae atesta a ocorrência de passagens nas seguintes pranchas: I, II, VI, VII, VIII, IX, X, XII, XIII, XVI, XXIV, XXIX, XXX, XL, XLI. Referências indiretas podem também ser encontradas em outras pranchas.

$\mathrm{Na}$ primeira prancha, Martius justifica o motivo de ter denominado as plantas da floresta Amazônica de Náiades. Segundo ele, a umidade da regiấo é muito alta e isso se deve principalmente às próprias plantas e às chuvas frequentes. Ele então afirma que "Netuno lhes é favorável" 21 . A intenção de Martius aqui parece ser meramente estética. Mas isso não é tudo. Se, na concepção cartesiana, só os seres humanos apresentam uma alma racional, e os animais e vegetais têm apenas uma alma sensitiva, para os românticos em geral, a natureza é plena de espíritos. A menção a Netuno, e mesmo a divisão da paisagem brasileira em reinos de diversas ninfas, é, sem sombra de dúvidas, também uma forma de se fazer referência ao caráter divino atribuído a ela em geral pelos autores românticos. Esse aspecto, como visto acima, está presente, de facetas variadas, tanto na filosofia de Schelling quando no pensamento de Goethe. As referências às ninfas e ao deus Netuno possivelmente também fazem parte de uma estratégia de antropomorfização da paisagem, em uma tentativa de despertar, por meio da reaçáo do leitor a essas metáforas, sentimentos e emoçôes de temor ou de amor que são mais facilmente despertados por um ser humano diante de outro ser humano.

$\mathrm{Na}$ segunda prancha, a referência ao universo clássico não é explícita. O texto original menciona a possibilidade de um botânico se deparar com pítons e crocodilos. Se os termos forem traduzidos literalmente, em vez de serem traduzidos de forma mais genérica por cobras e jacarés, não se trataria de animais passíveis de serem encontrados no Brasil, podendo ser, como assinalam os tradutores da edição brasileira da Flora Brasiliensi ${ }^{22}$, uma possível referência metafórica ao píton mitológico, à serpente ou ao dragão morto por Apolo na cidade de Delfos. A referência aqui, mesmo nesse caso, se houver, parece ter motivação eminentemente estética.

Na prancha seis, sobressaem as referências a Plínio, a Sêneca e a Lucrécio. Aqui elas assumem um caráter menos estético e mais filosófico, visando a despertar o leitor para o jogo de forças harmônico que constitui a natureza, lembrando a filosofia da natureza de Schelling. Também é ressaltado o

\footnotetext{
21 Martius 1996: 24.

22 Vide Martius 1996: 26 n. 1.
} 
caráter eterno da natureza. A analogia que é feita entre os túmulos de um cemitério e as plantas mortas em uma floresta constitui uma referência direta à ideia de imortalidade da alma.

Se quem entra num cemitério mal cuidado vê túmulos espalhados, sem flores, diligentemente plantadas ao seu redor e sem piedosos tufos de plantas que os cubram, misturando-se diante de seus olhos a terra nua, as pedras soltas e os pútridos ossos dos mortos mal escondidos, será tomado por horror e aversão. Longe estará, portanto, daquele outro estado de espírito, onde serenas imagens da morte são como imagens da vida que a virtude e a indulgência dos vivos derramaram sobre elas. $\mathrm{O}$ mesmo acontece na floresta. Por ventura não é ela mesma um cemitério, onde a vida de cada um, depois de ter florescido por um instante, recebe o abraço comum da morte? Além disso, não ignoramos que a ruína da geração precedente e sua passagem para o chão preparam sobretudo o lugar para uma nova disposição das coisas: quem aparece mais rápido também mais rápido se liga ao desenvolvimento de outro mais forte, assimilando-se a ele. Com isso extingue-se de todo o quadro a imagem da morte e da destruição de cada um, o que constringe o sentimento humano e de um certo modo entristece. Aqui vemos confirmadas as palavras de Sêneca: Diz-se que a natureza nada perde, porque aquilo que é tirado dela, a ela retorna; e coisa alguma pode ser destruída, porque náo tendo para onde ser levada, se volve sobre si mesma onde não deveria estar. De maneira semelhante diz o grande poeta Lucrécio:

Tudo o que retoma para seus corpos

A natureza dissolve sem destruir coisa alguma

Por isso nada parece totalmente acabar:

Quando a natureza faz de alguma coisa nascer outra

Deixa que o que nasce traga em si a morte alheia. ${ }^{23}$

Ao final da mesma prancha, o papel atribuído ao naturalista por Schelling, de coletar dados particulares para que a partir deles uma intuição acerca do funcionamento do todo possa surgir, parece sobressair.

23 Martius 1996: 35. 
Se contemplarmos a ordem natural desta sucessão de plantas descobrimos que existe algo de agradável que atrai e encanta o nosso espírito. $\mathrm{Na}$ verdade aprendemos aqui como uma grande quantidade de plantas diversas começa e acaba a vida, de acordo com a sua própria natureza, e como todos esses desdobramentos naturais estáo relacionados entre si e regidos por alguma lei maior. Esta lei sabe o que seja presente, passado e futuro. Ela não corresponde a uma necessidade cega da natureza, mas considera as condiçóes particulares que afetam inteiramente a vegetação, os períodos de seca e a umidade que as raízes absorvem e encaminham para a copa, pois mais cedo ou mais tarde as plantas hão de amadurecer e produzir seus frutos. Estáo reunidas as duas coisas, o que é próprio da natureza mesma da vegetação - e a alma a quem o criador dos mundos determinou que ligasse o movimento da vida terrestre à prosperidade das plantas e que assim um e outro, a vegetaçấo e a vida do planeta, se completassem. Seja-nos permitido lembrar as palavras de Sêneca: "A terra não conseguiria sustentar tantas e tâo grandes coisas, e inclusive a si mesma, se não estivesse cheia dessa alma que dia e noite se funde a todas as suas partes"24.

De nenhum modo me escapa que mesmo sendo tantas as mudanças e atividades no grande teatro da natureza elas possam ser inteiramente contempladas, ainda que estejam submetidas a leis intimamente relacionadas. É como o movimento de um relógio em que todas as peças obedecem a uma mesma lei física e em que todos os movimentos podem ser compreendidos por uma única apreensão da mente humana. Mas para mim esse ritmo de movimentos e mudanças que também se encontra em várias formas de plantas, parece depender de leis muito mais sutis e não propriamente desses mecanismos. Estes seres vivos, que concorrem aqui para um sistema táo maravilhosamente ordenado, trabalham segundo um mesmo princípio. Tudo isto acontece dentro dos amplos limites da atividade da vida orgânica que, pelo curso natural de cada coisa, permitem que haja algumas perturbaçóes e deformaçôes, origem daquelas mudanças que a natureza supera, combina e adapta. Eu não censuraria quem visse aqui aquela ideia de Platáo (no Timeu) segundo a qual o demiurgo determinou que representantes seus considerassem, para certas atividades orgânicas ligadas ao desenvolvimento do mundo, as açôes de cada coisa, ordenando-as e combi-

24 Martius 1996: 37-38. 
nando este mundo harmonioso desde o nascimento do indivíduo até o seu apogeu e daí até ao seu fim² ${ }^{25}$.

A crítica ao mecanicismo newtoniano e ao pensamento cartesiano fica evidente no trecho acima. Aqui claramente insinua-se a ideia da existência de uma força vital e uma perspectiva provavelmente teleológica da natureza, em contraposição à perspectiva causal-mecanicista cartesiana. Note-se também que a natureza é equiparada a um teatro, como se o que fosse observado fosse só, possivelmente, uma aparência, um lado externo da máscara do mundo, que, ao mesmo tempo que o oculta, o revela.

$\mathrm{Na}$ prancha sete, por sua vez, a natureza no Brasil é descrita como o Elísio humano.

Se é justo afirmar que o Brasil é uma das mais belas regióes do mundo, ao mesmo tempo deve-se dizer que é assim porque lá a natureza oferece à nossa vista diversíssimos e quase que opostos aspectos de beleza. A imensa quantidade de coisas, a inesgotável fecundidade da vegetaçáo, o extraordinário esplendor do céu que por toda parte favorece a vida humana, a encantadora formosura que se vê nos horizontes amenos, no perfil das montanhas, na distribuição das águas e dos rios, tudo isto não poderia produzir aquela terra belíssima, ou o elísio humano, como podemos chamar, se por todo lado as coisas se ordenassem do mesmo modo, obedecendo a um único movimento ${ }^{26}$.

Apesar de não ter sido diretamente mencionado, a referência a Heráclito e à ideia da harmonia de forças contrárias é evidente. O belo é o resultado de uma relação harmônica que surge a partir do contraste entre movimentos opostos.

Na prancha oito, de forma quase profética, aquele que é hoje um dos rios mais poluídos do Brasil, o rio Tietê, é equiparado ao Cócito: "tão logo nos afastamos das terras banhadas por este belo rio, entramos nos domínios do rio Tietê que dirige suas águas turvas como as do Cócito para os grandes rios Paraná e Paraguai" ${ }^{27}$.

Ao final da mesma prancha, Martius faz uma referência ao massacre dos índios nas terras brasileiras, com uma citação de Píndaro.

\footnotetext{
25 Martius 1996: 38.

26 Martius 1996: 40

27 Martius 1996: 42.
} 
Isto é o que podemos dizer das características desta regiáo. Ainda que eu deva mostrar como ficamos comovidos com esta floresta, percorrendo-a, contudo não posso negar que ela nos tenha parecido rude, triste e inóspita, do mesmo modo que nos pareceu ameaçador e feroz o aspecto dos primeiros habitantes que ainda viviam aí. Estes, originários do povo "caryôs" ou "guarûs", hoje se encontram privados de sua naçáo, dizimados pela varíola e pelas armas dos colonos cristáos. Alguns dos seus sobreviventes, dispersos e deformados, vivem entre os civilizados. Eles se acabam à maneira dos habitantes das sombras profundas. Como disse de cada um desses, de maneira excelente, o grande poeta dos tebanos: "Mas quem? Ninguém? O homem é um sonho de sombra". Isto vale também para os grandes povos: nenhum deles deixa vestígio e os ossos apodrecidos daqueles índios são cobertos pelas sombras indevassáveis da floresta que confirmam claramente o quanto a força vital das plantas supera a fragilidade dos homens ${ }^{28}$.

A prancha IX trata do espantar-se que dá origem à filosofia e que é a própria filosofia. Aqui é nítida a presença de um sentimento de sublime diante da natureza, que nos faz pensar na terceira crítica kantiana e na sua importância para a geração do movimento romântico.

Nessa prancha, uma máxima romântica é inicialmente destacada. É a ideia de que o mundo externo nada mais é do que um repositório das impressốes e dos sentimentos de cada indivíduo:

O espírito dos mortais, que sai de sua própria consciência como do mais profundo de si mesmo, difunde-se por toda a natureza. Os fenômenos e os corpos com que ele então entra em contato adquirem uma voz própria que lhes permite exteriorizar-se, e um coração próprio que pulsa com a força das paixóes, seja do amor ou do ódio. Esta voz das coisas, como uma imagem projetada delas mesmas, atinge o espírito humano, conforma-o, eleva-o. Na verdade, é o próprio homem que tira de si mesmo para atribuir às coisas exteriores tudo o que sente e pensa. Mas tudo isso retorna ao seu coração e o preenche e enriquece, como se ele estivesse recebendo, por meio da fala ou dos escritos, as opinióes e os pensamentos de outra pessoa ${ }^{29}$.

\footnotetext{
28 Martius 1996: 43-44.

29 Martius 1996: 45.
} 
Martius, então, descreve um sentimento de sublime diante das imensas árvores que contempla às margens do rio Amazonas, sensação semelhante nele despertada quando se deparou também com o imenso rio há pouco mencionado. Ele então afirma:

Ainda hoje aquelas árvores gigantescas me falam ao espírito e me enchem de um piedoso temor, ou me fazem vibrar no peito a mesma admiração inefável que tomava todo o meu ser. Esta admiração é a mesma que tomou conta de mim quando vi aquele rio largo e profundo, cujas ondas nem as razóes da inteligência nem os sentimentos do coração podem encontrar palavras com que descrever, pois as próprias palavras que nos sobrevêm e a emoção que sentimos dirigem o nosso espírito para aquele reino eterno e infinito em que só penetramos com uma pura e compungida veneração. É aquele "admirar-se" que Platão diz ser o início da filosofia, mas que eu considero ser o seu coroamento. Aquela audaciosa tentiva da inteligência de alcançar o absoluto, de descobrir o sentido do mundo, de conhecer com que finalidade ele é governado por Deus, de saber de onde surgiu a matéria ou de conhecer o bem e o mal que atingem o gênero humano - por ventura acreditarás que tudo isto é mais importante do que manter-se naquele temor respeitoso e naquela santa expectativa do espírito que se maravilha diante de todas essas $\operatorname{coisas}^{30}$ ?

A referência aqui é a passagem 155 d do Teeteto: "é próprio do filósofo a paixão pelo admirar-se; não há outro princípio da filosofia a não ser este"

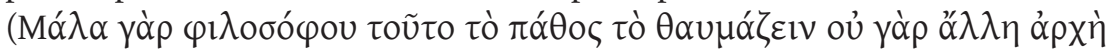
$\varphi \imath \lambda о \sigma o \varphi i ́ \alpha \varsigma$ ทे $\alpha u ̈ \tau \eta)$. É fundamental que seja notada, na passagem acima, uma certa crítica ao conhecimento sem piedade, sem a reverência diante do imenso desconhecido e do maravilhar-se diante do mundo, atitude que Martius diz ser condizente com a sua própria natureza e à qual ele foi levado pela sua admiração por Platão:

Estas considerações é que nos mantêm presos não a uma meditação estreita, mas a uma concepçáo piedosa com que preparamos o espírito para a compreensão de todas as coisas que Deus colocou diante de nós, de acordo com seus desígnios, a fim de que, com a sua exortaçáo, a mente e o coração do homem sejam tocados com o sopro inflamado da

30 Martius 1996: 45-46. 
aura divina, desta aura que por toda a parte reina, cria, alimenta e que, onde quer que esteja, se oferece para ser ouvida com o clamor da sua voz. Eu confesso francamente que sou um partidário dessa filosofia e até ouso aqui defendê-la. Depois de conhecer a verdade e penetrar mais profundamente no sentido das coisas divinas, estudei por mais tempo estas coisas e, com aquela dedicação que é própria do jovem honrado, me entreguei a essas rochas secas e a esses bancos de areia de meditaçóes táo fatigantes. Mas da natureza por um impulso interior, que não se origina apenas do entendimento, mas principalmente do espírito, que este ímpeto alimenta e estimula, fui levado da consciência de Deus, o que é inato em mim, para a admiração por Platão. E desta fonte límpida meu coração sedento bebeu a doce consolaçấo e encontrou o desejado repouso do espírito ${ }^{31}$.

Martius parece, portanto, pretender repetir no seu leitor a mesma experiência de admiração que ele teve, a partir das descriçóes por ele apresentadas e das belas imagens ali expostas. Com isso, a sua narrativa parece assumir uma perspectiva pedagógica, constituindo uma espécie de Bildungsreise, viagem de formação, tão típica do Renascimento, quando a Itália era considerada lugar ideal para adquirir conhecimentos científicos e artísticos. Assim, ele permite que aqueles que não têm os recursos que ele possui para participar de tal empreitada, também realizem, por meio de seu relato, a sua viagem de formaçáo. Ele se constitui em uma espécie de condutor de almas e, a natureza brasileira, o cenário ideal para essa viagem. Se no mundo externo encontram-se as projeçoos do mundo interno dos indivíduos, nessa perspectiva romântica, o relato sobre a viagem pelas terras brasileiras pode, assim, se converter em uma viagem pessoal para um conhecimento de si. Os lugares por ele descritos, paraísos e infernos no meio da natureza brasileira, podem, então, talvez ser pensados como lugares da alma humana.

\section{Consideraçóes finais}

As obras escritas pelos viajantes são marcadas pelos contextos histórico-culturais das épocas em que foram escritas. Revelam muito da forma como a identidade europeia é construída, assinalando especialmente o modo como cada cultura observa a outra, como analogias são traçadas em torno

\footnotetext{
31 Martius 1996: 46.
} 
de semelhanças e diferenças imaginadas pelos viajantes, a partir da projeção de elementos de sua cultura. Martius, imerso na filosofia da natureza romântica, influenciado especialmente pelo pensamento de Schelling e de Goethe, e pela proposta estética de Humboldt, viaja por dois mundos em que projetará seu olhar europeu: o mundo antigo e o novo mundo. É a partir dessa triangulação de olhares, da projeção do imaginário romântico europeu, sobre as novas terras e sobre a antiguidade clássica, que, em última instância, um olhar não só para esses dois mundos, mas, sobretudo, para o homem europeu e para si mesmo, é elaborado, permitindo que, nesse jogo de reflexos, a sua própria identidade possa ser repensada. Isso é sintetizado por ele mesmo ao final de sua prancha IX, após citar a Antígona de Sófocles:

De todo animal que a terra sustenta e nutre, nenhum existe que possa atingir a força de antiguidade daquele gigante a não ser o homem. Pois só ele pode derrubar aquele vigorosíssimo e antiquíssimo tronco com o ferro de seu machado. Só ele tem o poder de mudar todas as coisas que o circundam. É o que nos lembra Sófocles verdadeira e tristemente (Antigona 332):

"Muitas coisas são terríveis, mas não tão terríveis quanto o homem." Mas ainda que se considerando um vitorioso sobre todas as coisas, o homem há de se voltar sobre si mesmo e se perguntar quem ele é, quem é este Prometeu a quem nada restou senão a admiração por si mesmo, como se ele estivesse realmente convencido de pertencer a uma descendência de deuses. ${ }^{32}$

32 Martius 1996: 49. 


\section{Alexandre Schmitt}

\section{Bibliografia}

Foster, R. (2008), The Creativity of Nature: The Genesis of Schelling's Naturphilosophie, 17551799. Doctoral Thesis. Department of Philosophy. Houston: Rice University.

Humboldt, A. (1808), Ansichten der Natur mit wissenschaftlichen Erläuterungen. Tübingen: Cotta.

Humboldt, A. (2005), Cosmos: Ensayo de una descripción fisica del mundo. I. Madrid (18511852), Córdoba: Universidad de Córdoba.

Lisboa, K. M. (1997), A nova Atlântica de Spix e Martius: natureza e civilização na Viagem pelo Brasil (1817-1820), São Paulo: Editora Hucitec.

Martius, C. F. P. (1996), A Viagem de von Martius. Flora Brasiliensis. I. Tradução de Matheus, C. B., Barreto, L. L. P, Rosário, M. B. Rio de Janeiro: Objectiva.

Mazzari, M. V. (2010), "Natureza ou Deus: afinidades panteístas entre Goethe e o "brasileiro" Martius", Estudos Avançados 24 (69): 183-202.

Springer, K. (2009), "Consideraçóes acerca da Geografia de Alexander von Humboldt: teoria: filosofia e concepção de natureza”, Rảe $G a$. 18: 7-22.

Vitte, A. C. (2006), "Da metafísica da Natureza à gênese da Geografia Moderna”, GEOgrafia, 15: 23-50. 
Maria de Fátima Sousa e Silva é Professora Catedrática do Instituto de Estudos Clássicos da Universidade de Coimbra. Desenvolveu, como tese de doutoramento, um estudo sobre a Comédia Grega Antiga (Crítica do teatro na Comédia Grega Antiga), e, desde então, tem prosseguido com investigação nessa área. Publicou já traduções comentadas de nove comédias de Aristófanes, além de um volume com a tradução das peças e dos fragmentos mais significativos de Menandro.

Maria das Graças de Moraes Augusto é Professora Titular no Departamento de Filosofia do Instituto de Filosofia e de Ciências Sociais da Universidade Federal do Rio de Janeiro (UFRJ). A sua investigação sobre História da Filosofia Antiga abrange temas como Platão e a herança platónica, filosofia e conhecimento no pensamento antigo, filosofia e literatura na tradição antiga e recepção dos clássicos gregos no Brasil.

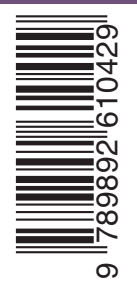


OBRA PUBLICADA

COM A COORDENAÇĀO

CIENTÍFICA
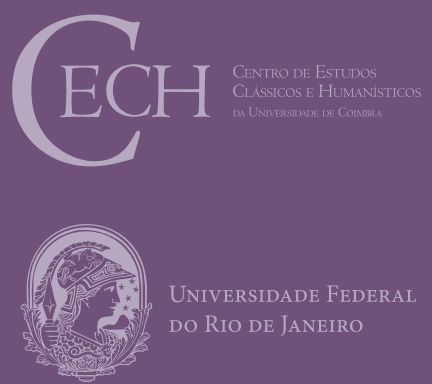

- U 